\title{
A POLICY PATHWAY TO REDUCING TEENAGE PREGNANCY IN AFRICA
}

\author{
Opeyemi Odejimi ${ }^{1}$, Denise Bellingham-Young ${ }^{2}$
}

\begin{abstract}
Background: Teenage pregnancy remains an important and complex issue around the world, with reports indicating that Africa has higher rates than other continents. Studies have indicated that social and economic determinants are associated with these higher rates. Therefore this study aims to identify the social and economic influencers of teenage pregnancy which would help develop a best-practice approach to reduce its incidence in Africa. Methods: Data sets from the World Bank Organisation between 2008 and 2010 specific to 51 Africa countries were obtained to conduct this study, based on availability. Independent t-test, Spearman's correlation and regression analysis were performed. The eight social and economic variables used in this study are: GDP per capita, GINI index, Female Literacy rate, Health expenditure, Unemployed female rate, Gender equality, Contraceptive prevalence and urban population rate. Results: Independent t-test revealed that in countries where teenage pregnancy rate is high, Literacy rate, contraceptive prevalence rate and Healthcare expenditure rate was low. Spearman correlation indicated that female literacy rate, Healthcare expenditure, GDP per capita and Contraceptive prevalence had a significant inverse relationship with teenage pregnancy rate. Logistic regression indicates that Female Literacy rate is the best predictor of teenage pregnancy in Africa. Conclusion: Result suggest that a practical approach to reduce teenage pregnancy rate in Africa is to implement strategies and policies aimed at improving female literacy rate, Health care expenditure and the GDP per capita of a country. Additionally, an increase in female literacy rate would concurrently increase Contraceptive prevalence rate.
\end{abstract}

Key words: Teenage pregnancy, social and economic determinants, Africa policy.

\section{INTRODUCTION}

Teenage pregnancy remains an important and complex issue around the world ${ }^{1,2}$. This is majorly attributed to the numerous health consequences such as pregnancy related illness, high infant mortality rate, low birth weight babies, maternal mortality and exposure to sexually transmitted diseases ${ }^{3}$.

Asides the medical consequences, there are several economic and social consequences associated with high teenage pregnancy rate ${ }^{4,5}$. This is because teenage pregnancy causes an upsurge in a nation's population which places a burden on other sectors of the economy, hence, impeding the economic and social progress of such nations ${ }^{6}$; furthermore, this can lead to extreme poverty especially in lower income countries ${ }^{7}$.

The rate of teenage pregnancy varies between developed and developing countries. According to World Health Organisation (WHO) report 8 , the global teenage pregnancy rate was projected to be 54 births per 1000 women for 2000-2005 periods. Furthermore, WHO report ${ }^{9}$ states that the average teenage birth rate amongst developed countries was 29 births per 1000 with European countries having the lowest rate; whereas, in developing countries teenage pregnancy rate was as high as 133 births per 1000 females.

The World Health Statistics review ${ }^{10}$ indicates that the average teenage pregnancy rate across Africa is about 118 per 1000 females and this figure is very high when compared to the rate in other continents. Some researchers have stated that the high teenage pregnancy rate in Africa can be attributed to Africa being amongst the poorest continents of the world with most countries underdeveloped ${ }^{11}$.

Dev Raj et al. ${ }^{14}$ in a systematic review on factors associated with teenage pregnancy in South Asia identified that in developing countries, social and economic determinants associated with high teenage pregnancy rate are: socioeconomic condition; low educational attainment; as well as cultural and family structure.

This opinion is further supported by The World Bank synopsis ${ }^{15}$ on the determinants of

1 Masters of Public Health, School of Health and Wellbeing. University of Wolverhampton, United Kingdom.

2 Senior Lecturer at School of Health and Wellbeing, University of Wolverhampton, United Kingdom. Corresponding author: opeyemi.odejimi@gmail.com

Suggested citation: Odejimi O, Bellingham-Yong D. A policy pathway to reducing teenage pregnancy in Africa, Journal of Human Growth and Development, 24(2):135-141

Manuscript submitted Aug 01 2013, accepted for publication Dec 282013. 
increased fertility in low income countries. The Synopsis ${ }^{15}$ reported that poor access to sexual health services and urbanisation were also determinants of teenage pregnancy amongst developing countries.

Figure 1 illustrates the social and economic determinants that influences teenage pregnancy rate in Africa. The relationship between the social and economic factors with teenage pregnancy rate is such that each of the underlying social and economic factors could either increase or decrease teenage pregnancy rate and at the same time this factors influences one another.

Due to the numerous impacts of the high teenage pregnancy rate in Africa, there is a need to put in place a policy that addresses the issue of teenage pregnancies in Africa. Recent studies carried out in some African countries have identified factors such as low educational attainment in Kenya12 and poor use of contraceptive in Morocco ${ }^{13}$ and therefore suggested policies around such factors.

There is however still a need to investigate other factors associated with high teenage pregnancy rate in Africa. Therefore, this research paper aims to examine social and economic factors unique to African nations in an attempt to understand the high prevalence in Africa; thereby suggesting a policy pathway which can be used in informing policy makers on the determinants of teenage pregnancy in order to plan targeted interventions.

\section{METHODS}

\section{Data and methods}

This study used data from the World Bank Organisation conducted between 2008 and 2010 in Africa ${ }^{16}$. Data from 51 African countries were included in this study. Countries were selected for inclusion based on availability of comparable data sets on teenage pregnancy rate.

\section{Ethical considerations}

This study is based on an analysis of existing survey data and does not involve any form of contact with human or animal subjects. Data sets utilised in this study have been obtained from the World Bank Organisation freely within the public domain. In addition, these data sets do not contain any information that can breech confidentiality of the participants. Therefore, there are no ethical issues to be considered for this study as it poses no harm to the participants.

\section{Variables}

The main dependent variable is the teenage pregnancy rates in the countries which represent the number of births per 1000 women aged 1519. The independent variables aim to determine the individual characteristics of the countries and generate correlations. These independent variables are:

- GINI index: it is a measure of a countries level of income inequality and expresses. This ranges from 0-100, with zero and 100 signifying perfect equality and inequality respectively. It is assumed based on Daw Namoro ${ }^{17}, 18$ study that the higher a country's income, the higher the teenage pregnancy rate.

- GDP per capita: This indicates the general standard of living in a country which can be determined by the level of income of individuals

Figure 1: illustration of the social and economic determinants of teenage pregnancy in Africa

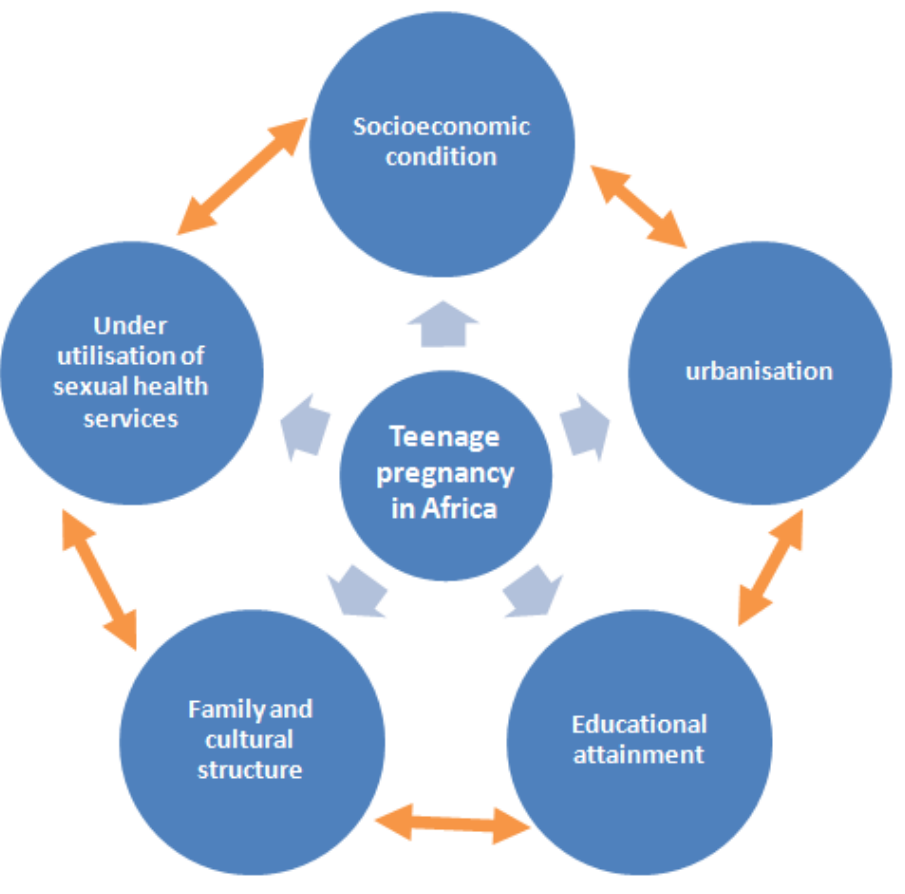


living in a country. This rate is usually expressed in US Dollars (\$). In line with previous study by The World Bank Synopsis ${ }^{15}$ it is expected that the higher the standard of living (the higher the level of income) the lower the teenage pregnancy rate.

- Female Literacy rate: This is the number of females' ages 15 to 24 years who can both read and write and understand short simple statements. Following recent research ${ }^{14,15,19}$. It is expected that the more adolescent females are educated, the less likely they would be involved in unsafe or underage sexual activity.

- Urban population rate: It refers to the number of people living in urban areas in a country. in line with previous studies ${ }^{9,12,13,15}$ it is presumed that the more females living in urban areas the lower the teenage pregnancy rate, as they would engage in more profitable activities in urban regions.

- Contraceptive prevalence: This is the proportion of women aged 15-49, who are practicing, or whose sexual partners are practicing, any form of contraception. in line with previous research $9,14,19,20,21,22,23,24$ it is expected that the higher the numbers of women practicing any form of contraception, the lower the teenage pregnancy rate.

- Health care expenditure: It is the sum of public and private health expenditure, and It covers the provision of both preventive and curative, as well as family planning activities, nutrition activities, and emergency aid. it is expected that in line with studies by Dev Raj et al. ${ }^{14} 2010$ and Isaranurug et $\mathrm{al}^{25}$ the more a Government spends on health care the lower the teenage pregnancy rate.
- Gender equality: This measures the extent to which a country has installed institutions and programmes to enforce laws and policies that promote equal access for men and women to education, healthcare services, the economy, and protection under law. It ranges from 1-6 with 1 signifying low and 6 high. It is expected based on the study by Were ${ }^{12}$ that the higher the gender equality of a country the lower the teenage pregnancy rate.

\section{DATA ANALYSIS}

Data Analysis in this study was carried out in various steps. First descriptive analysis was carried out to derive the median of all variables. Thereafter, all variables were recoded and categorised into 2 groups using the median, with values below the median classified as Group 1 and values above the median classified as Group 2 and an Independent t-test was carried out.

Next, Spearman's correlation analysis was used to derive if there is any association between the dependent variable and each of the independent variable. IBM SPSS Statistics 19 was the statistical package used in conducted the analysis for this study. Thereafter, logistic regression was carried out to identify the predictors of teenage pregnancy in Africa.

\section{RESULTS}

Using a median of teenage pregnancy to create two groups, independent t tests were conducted. Results can be seen in table 1 below which shows the mean for each variable above and below the median teen age conception rate along with the value of $t$ and probability.

Table 1: $t$ test of teenage pregnancy rate above and below the mediaIn African countries where teenage pregnancy rate is above the median, literacy, healthcare expenditure and contraceptive prevalence is significantly lower

\section{VARIABLE}

Literacy rate

Contraceptive prevalence

Health care expenditure
TEENAGE PREGNANCY ABOVE MEDIAN

66.6

22.05

77.78

\section{BELOW MEDIAN}

87.4

40.67

179.52
T TEST

t 4.146, df 34, p.000

t 2.58, df 18, p.019

t 2.209 , df 47, p.032
Spearman correlation was conducted to explore the relationship between variables, results for can be seen in Table 2 below. Significant correlations can be seen in bold. Level of significance is indicated by $*$ where $\mathrm{p}<0.05$ or $* *$ where $\mathrm{p}<0.001$.

Significant strong negative correlation emerged with literacy and contraceptive prevalence rate and a significant moderate negative correlation with GDP per capita and healthcare expenditure indicating that In African countries where literacy rate, contraceptive prevalence, GDP per capita and health care expenditure are higher, teenage pregnancy rate is lower.

There was a significant strong positive correlation between GDP per capita with health care expenditure and contraceptive prevalence and a significant moderate positive correlation between GDP per capita and literacy rate, denoting that in African countries with high GDP per capita, literacy rate, contraceptive prevalence and health care expenditure will equally be high.

A significant moderate negative correlation was noted between literacy rate and urban 
population rate, implying that in African countries where a greater proportion of the population are urban dwellers, literacy rate is lower. Also a strong positive relationship emerged between contraceptive prevalence and health care expenditure suggesting that in countries with high contraceptive prevalence, health care expenditure would also be high.

Furthermore, a significant strong relationship was observed between literacy rate with contraceptive prevalence rate and healthcare expenditure, illustrating that in African countries where literacy rate is high, contraceptive prevalence rate and healthcare expenditure is also high.
To explore key predictors of teenage pregnancy rate, a logistic regression model with teenage pregnancy rate as the predicted (dependent) variable and GDP per capita, Health Care Expenditure and Literacy was significant ( $f 4.64, \mathrm{p}=.000)$ accounting for $32 \%\left(r^{2}=.317\right)$ of variance in teenage pregnancy rate in Africa. Increasing literacy by 1 unit is predicted to reduce teenage pregnancy by 94 per $1000(b=-.935$, $p=0.037)$. An increase by 1 unit of expenditure on health care is predicted to reduce teenage pregnancy rate by 37 per 1000 ( $b=-.369$, $\mathrm{p}=0.05)$. Interestingly a unit increase in GDP is predicted to increase teenage pregnancy rate by 1.7 per $1000(b=0.17, \mathrm{p}=.042)$.

Table 2: Correlation results with significant results in bold (Level of significance is indicated by $*$ where $\mathrm{p}<0.05$ or $* *$ where $\mathrm{p}<0.001$ )

\begin{tabular}{|c|c|c|c|c|c|c|c|c|}
\hline & 1 & 2 & 3 & 4 & 5 & 6 & 7 & 8 \\
\hline \multicolumn{9}{|l|}{ Teenage pregnancy } \\
\hline GINI index & -.311 & & & & & & & \\
\hline GDP per capita & $-.399^{* *}$ & .086 & & & & & & \\
\hline Literacy rate & $-.528^{* *}$ & .095 & $.483^{* *}$ & & & & & \\
\hline Gender equality rate & -.152 & .122 & .150 & .291 & & & & \\
\hline Contraceptive prevalence rate & $-.517^{*}$ & -.086 & $.574^{*}$ & $.900^{* *}$ & .459 & & & \\
\hline Urban proportion & .139 & -.174 & -.080 & $-.395^{*}$ & -.093 & .006 & & \\
\hline Health care expenditure & $-.472^{* *}$ & .074 & $.907^{* *}$ & $.649^{* *}$ & .153 & $.537^{*}$ & -.141 & \\
\hline
\end{tabular}

As literacy emerged the key predictor of teenage conception, we explored predictors of literacy rate. A further logistic regression model with literacy rate as the predicted (dependent) variable and GDP per capita, urban population, contraceptive prevalence and health care expenditure as the predictor (independent) variables accounted for $80 \%$ of variance in literacy rate $\left(r^{2}=.799\right)$. Within this model the significant predictor was contraceptive prevalence indicating that a unit increase in contraceptive prevalence predicts an increase in literacy rate of .97 $(b=.967)$.

\section{DISCUSSION}

The purpose of this research is to suggest a policy pathway that can reduce teenage pregnancy rate in Africa. Findings from this study have shown that health care expenditure, female literacy rate and GDP per capita are predictors of teenage pregnancy with literacy rate being the key predictor. Thus, indicating that the determinants of teenage pregnancy in Africa are multifaceted.

The evidence that literacy rate is a major determinant of teenage pregnancy rate is in accordance with previous studies. A study carried out by Were ${ }^{12}$ indicates that less than $50 \%$ of the teenage mothers who took part in the study had completed primary education, and nearly $62 \%$ dropped out when they became pregnant. The Health Development Agency ${ }^{26}$ also expressed a similar opinion stating that a considerable amount of teenage mothers are more likely to drop out of school while pregnant.

Furthermore, Lemos ${ }^{27}$ study stated that literacy rate is a key predictor of an individual's socioeconomic status which is also one of the determinants of teenage pregnancy. The author further reveals that within poor socioeconomic groups with low educational attainment teenage pregnancy was twice that observed in similar poor socioeconomic communities with better educational attainment.

This explains why Were ${ }^{12}$ and Sharma et al ${ }^{28}$ stated that literacy rate is both a cause and a consequence of high teenage pregnancy rate in developing countries. This is because individuals with low literacy level have a higher chance of: living in poverty; being in low paid jobs; or unemployed as rightly pointed out by Hobcraft et $\mathrm{al}^{29}$. Thus, teenage parents may end up becoming deprived families, and the vicious cycle continues ${ }^{30}$.

This study also demonstrates that as healthcare expenditure and contraceptive prevalence increases, teenage pregnancy decreases. This is line with previous assumptions made. According to $\mathrm{WHO}$ report $^{19}$ there was an $8 \%$ increase in the use of contraception globally between 1990 and 2007; however, the proportion of increment recorded in Africa appears to be the lowest.

An explanation given by $\mathrm{WHO}$ report $^{24}$ and Gogna et $\mathrm{al}^{21}$ for this decrease in the use of contraception and healthcare facilities is that in several developing countries public health 
measures such as: sex and relationship education; sexual development; methods of preventing pregnancies; and sexually transmitted diseases are either inadequate or absolutely lacking.

Furthermore, this study demonstrates that in countries where GDP per capita is higher, female literacy rate, contraceptive prevalence and health care expenditure is also higher. This finding is in accordance with previous research ${ }^{19}, 21,24$ which clearly indicate that in countries with high GDP per capita more females would be able to engage in skilled labour and have a good standard of living.

Besides, such countries with high GDP per capita would have more healthcare facilities which would be easily accessible and even preventative measures such as: use of contraceptives, advice and counselling; as well as sex and relationship education can be taught in such healthcare facilities; Thus, further reducing the teenage pregnancy rate in such countries.

However, the researchers also recognises that in countries with high GDP per capita, female literacy rate, contraceptive prevalence and health care expenditure could remain low due to issues such as female discrimination and oppression. This is why $\mathrm{WHO}^{31}$ has stated that in such countries, health promotion activities that utilises education, negotiating and training can be used in addressing this issues. Other interventions suggested are: imposing laws and setting up reproductive rights tribunals.

This research also revealed that in countries where literacy rate is high, urban population is reduced. This finding is in line with previous studies by Abdesslam ${ }^{13}$ and Were ${ }^{12}$ which clearly states that many young females in Africa move from rural regions to urban regions in search for higher educational attainment, paid employment and better health care facilities. Hence, teenage pregnancy would be reduced in such countries.

Nevertheless, the researchers recognises that the assumption that an increase in urban population results in a reduction in teenage pregnancy rate is contrary to the study by Imamura et al22 which stated that teenage pregnancy is now higher in urban regions of developing countries. This could possibly be due to high deprivation faced by urban region migrants. This sometimes bring about such migrants abandoning their aspirations of higher education or better employment and subsequently engaging in unsafe sexual practices to survive the harsh conditions in the urban regions.

A possible explanation for the nonsignificant result of GINI index and Gender equality is the format in which the available data were presented; as both data sets were in index format. Although the results of GINI index result was not in accordance with the expected direction. Likewise, urban population showed a nonsignificant result but in the expected direction. A possible explanation is that the figures for urban population rate not specific for females but the entire population in a country.

These results from the study has enabled the researchers to develop a conceptual model shown in figure 2 below that shows a suggested policy pathway that can be used to reduce teenage pregnancy in Africa.

Figure 2: suggested pathway to explain teenage pregnancy in Africa

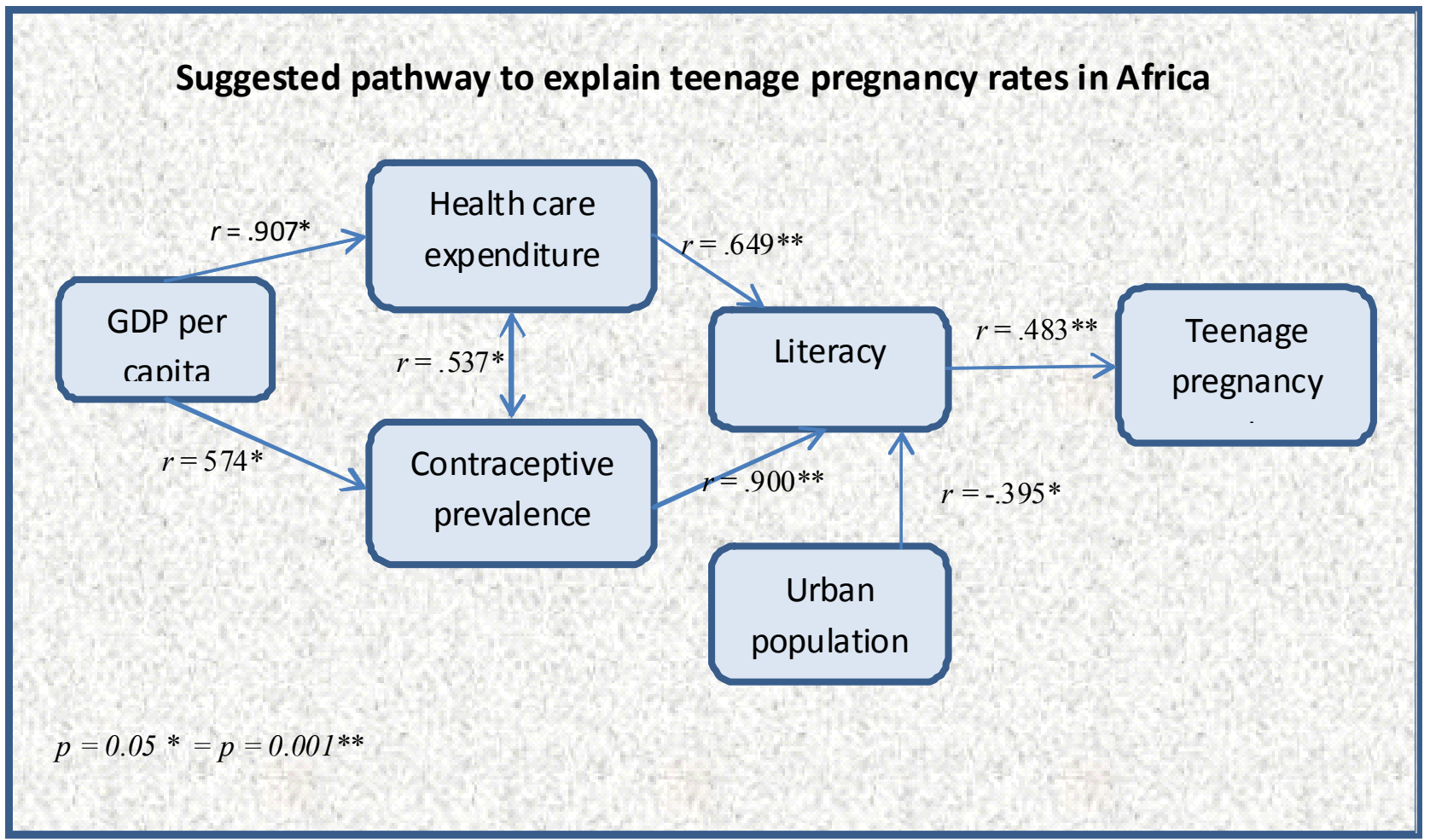


Within the framework we suggest that increases in GDP per capita will enable the government put in place policies and strategies that facilitate increase in health care expenditure and contraceptive prevalence. The bidirectional arrow between health care expenditure and contraceptive prevalence is indicative of the inter relatedness of these variables, with one affecting the other.

The position of literacy rate within the policy pathway is drawn from the regression results that indicate healthcare expenditure and contraceptive prevalence are key predictors of literacy rate. Hence, policy that influences these two variables would impact upon literacy rate. Besides, policies should also pay attention to increasing literacy rate amongst urban dwellers.

The findings of this research can be considered in the light of the following limitations: first, due to the non-availability of recent data sets of some other important social and economic determinants such as, age at marriage of females, female occupational status and female income, such social and economic determinants could not be measured. Second, the format of the available data could underestimate the influence of the determinants of teenage pregnancy had it been that all the data sets used the same indicators.

Despite these limitations, this research study has some significant strength. First of all, it is a large population-based study with national coverage of all countries in Africa and the findings from this study are representative of the continent. In addition, this study is unique in that it adds wealth of knowledge on the determinants of teenage pregnancy in Africa by exploring the impacts of several social and economic factors.

Besides, the data sets used were from the World Bank Organisation which have some important advantages when compared with other surveys, in that not only are they nationally representative but also contain data sets of some important variables that made it possible to carry out the necessary analysis.

Although, thorough research has been conducted to investigate the impact of several social and economic factors on teenage pregnancy; however, there are other related areas that could benefit this work in tackling teenage pregnancy in Africa. For instance, future research could focus on the barriers to implementing educational services as well as sex and reproductive education in secondary schools.

\section{REFERENCES}

1. Dangal, G. (2005) An update on teenage pregnancy. The Internet Journal of Gynaecology and Obstetrics [online]. 5(1) [Accessed 6 December 2011]. Available at: : < http:// .ispub.com>

2. Gallaghers, M. (1999) The age of unwed mothers. Is teen pregnancy the problem? New York: Institute for American Values.
In addition, further research on some variables such as: urban population rate specific for females, age at marriage of females, female occupational status and female income can help in identifying other social and economic determinants essential in reducing the teenage pregnancy rate in Africa.

Furthermore, future research can also be conducted to compare the teenage pregnancy rate and other socioeconomic factors in countries where policies on compulsory education for teenage females and reproductive rights have been implemented to ascertain the effectiveness of such policies.

\section{CONCLUSION}

This study indicated that determinants of teenage pregnancy in Africa are multifaceted with social and economic determinants such as: GDP per capita, literacy rate, contraceptive prevalence rate and healthcare expenditure rate emerging as great influencers of teenage pregnancy in Africa.

However, in other to prioritise due to the limited available resources, particularly in Africa where a number of the countries are developing countries, a policy pathway based on the best predictor of teenage pregnancy in Africa has been suggested by the authors.

A policy pathway to reduce teenage pregnancy rate in Africa is one that puts in place policies and strategies to increase female literacy rate. This will increase both the use of contraception amongst female and the healthcare expenditure. The overall effect would be an increased GDP per capita of the nation.

Besides an increase in literacy rate would also reduce rural-urban migration as more educated females within the rural region would utilise the skills and knowledge gained while in education to develop their communities. Furthermore, policies that increase female literacy rate in Africa would help ensure that: schools are located in the right site; trained individuals are available; free and affordable education are given to citizenry; as well as ensuring individuals are literate enough to understand the sex and relationship education given.

Likewise, an increase in female literacy rate would help disabuse myths and misconception. Thus, allowing the ease of public health measures that increases access to healthcare facilities and the use of contraception.

3. World Health Organisation (2006) Pregnant Adolescent: delivering on global promises of hope. Geneva: World Health Organisation.

4. Buvinic, M., and Kurz, K. (1998) Prospects for young mothers and their children: a review of the evidence on consequences of adolescent childbearing in developing countries. Paper presented at The Committee on Population, National Research Council, National Academy of Sciences Workshop on Adolescent 
Reproduction in Developing Countries, March, 24-25: Washington.

5. World Health Organization (1996) Adolescent health - Inter country Consultation on the promotion of health of adolescent girls through maternal and child health programmes. Nicosia, Cyprus: World Health Organisation.

6. Aoyama, A. (2001) Reproductive health in the Middle East and North Africa: well-being for all [online]. World Bank. [Accessed 18 November 2011]. Available at: http://site.ebrary.com/lib/ wolverhampton/>

7. Agbemenu, K. (2011) An integrated review of comprehensive sex education for adolescent girls in Kenya. Journal of nursing scholarship. 43 (1). pp 54-63.

8. World Health Organization (2002) Essential care: practice guide for pregnancy, childbirth and new born care. Geneva: World Health Organization.

9. World Health Organisation (2007) Adolescent pregnancy - Unmet needs and undone deeds. A review of the literature and programmes. Issues in Adolescent Health and Development. Geneva: World Health Organisation

10. World Health Statistics (2011) World Health Statistics report, 2011. France: World Health Organization. 2011.

11. United Nation Development Programme (2003) Millennium development goals: A compact among nations3333 to end human poverty. New York: United National Development Programme

12. Were, M. (2007) Determinants of teenage pregnancy: The case of Busia district in Kenya. Economics and human biology $5 \mathrm{pp}$. 322- 339

13. Abdsselam, B. (2011) Social Determinants of Reproductive Health in Morocco. African Journal of Reproductive Health. 15(2) pp.55-66.

14. Dev-Raj, A., Rabi, B., Amudha' P., Edwin, V., and Glyn, C. (2010) Factors associated with teenage pregnancy in South Asia: a systematic review. Health Science Journal. 4(1), pp3-14.

15. World Bank (2010) Determinants and Consequences of High Fertility: A Synopsis of the Evidence. Washington: World Bank Organisation.

16. World Bank Group (2012) The World Bank open data [online]. World Bank: New York. [Accessed 20 May 2012]. Available at: <http:/ /data.worldbank.org/indicator>.

17. Daw-Namoro, S. (2009a) The Not-So-Visible Determinants of Youth Reproductive Health in Sub-Saharan Africa. University of Pittsburgh. pp1-20.

18. Daw-Namoro, S. (2009b) Youth Reproductive Health in Sub-Saharan Africa. Is Governance Part of the Problem? University of Pittsburgh. pp1-20.
19. World Health Organisation (2012) Early Marriage Adolescent and Young pregnancies. Report by the secretariat. Geneva: World Health Organisation.

20. Ewles, L. (2005) Key topics in public health: essential briefings on prevention and health promotion. Edinburgh: Elsevier Churchill Livingstone.

21. Gogna, M., Binstock, G., Fernandez, S., Ibarlucýa. I., and Zamberlinc, N. (2008) Adolescent Pregnancy in Argentina: EvidenceBased Recommendations for Public Policies. Reproductive Health. 16(31), pp.192-201.

22. Imamura, M., Tucker, J., Hannaford, P.,Oliveira da Silva, M., Astin, M., Wyness, L., Bloemenkamp, K., Jahn, A., Karro, H., Olsen, J., and Temmerman, M. (2007) Factors associated with teenage pregnancy in the European Union countries: a systematic review. European Journal of Public Health, 17(6), pp.630-636.

23. Tripp, J., and Viner, R, (2005) ABC of adolescence Sexual health, contraception, and teenage pregnancy. British Medical Journal. 330, pp.590-593.

24. World Health Organisation (2004) Adolescent Pregnancy: Issues in adolescent health and development. Geneva: World Health Organisation.

25. Isaranurug, S., Mo-suwan, L., and Choprapawon, C.(2006) Differences in SocioEconomic Status, Service Utilization, and Pregnancy Outcomes between Teenage and Adult Mothers. Journal of Medical Association Thailand. 89 (2), pp.145-51.

26. Health Development Agency (2003) Teenage pregnancy and parenthood: a review of reviews. Evidence briefing. London: Health Development Agency.

27. Lemos, G. (2009) Freedom's consequences: Reducing teenage pregnancy and their negative effects in the UK. [online]. Report by the Monument trust, Lemos \& Crane. [Accessed 5 January 2012]. Available at: http:// www.lemosandcrane.co.uk/home/resources/ fq_dl865rte.pdf

28. Sharma A., Verma K., Khatri S., Kannan A. (2002) Determinants of pregnancy in adolescents in Nepal. Indian Journal of Paediatrics. 69: pp.19-22.

29. Hobcraft, J. and Kiernan, k (1999) Childhood poverty, early motherhood and adult social exclusion. CASE paper 28. London: London School of Economics.

30. Gökçe, B., Ozsqahin, A., and Zencir, M. (2007) Determinants of adolescent Pregnancy in an urban area in Turkey: a population-based Case-control study. Journal of Biosocial Science. 39, pp.301-311.

31. World Health Organisation (2001) Advancing Safe Motherhood through Human Rights. Geneva: World Health Organization. 